\title{
AGGRESSIVE DRIVING IS A MAJOR CAUSE OF TRAFFIC ACCIDENTS AND ROAD RAGE IN JORDAN
}

\author{
Mohd R. Suliman and Wa'el H. 'Awad \\ Department of Civil Engineering \\ Faculty of Engineering Technology \\ Al-Balqa' Applied University \\ P.O. Box 15008, Amman, Jordan 11134 \\ E-mail: whawad@fet.edu.jo
}

\begin{abstract}
Summary: Motor vehicle accidents are a major cause of death among Jordanians. Roughly 700 people died last year in car accidents out of a total population of five million people. Many factors contribute to this. Some involve planning, design, construction, operation, surface condition, and policing of the roadways. The most deadly factor is human error. This includes unawareness of traffic rules and roadway condition; lack of driving skills; poor judgment; failure to interact and adjust to prevailing roadway conditions; and most importantly, aggressive driving. Preliminary findings of a survey questionnaire conducted in this study show that improper engineering design, inadequate traffic control, lack of traffic management, and traffic congestion are the main factors leading to aggressive driving and road rage on Jordan roadways. The study includes 200 questionnaires.
\end{abstract}

The main objective of this study is to identify aggressive driving behaviors in Jordan and underline their effect on traffic safety. In addition, the study attempts to increase drivers' awareness of their actions on the roadway and point out the consequences associated with these actions. Many drivers justify their aggressive driving as temporary retaliatory measures to counteract other aggressive drivers, and therefore, this leads to road rage and traffic chaos. Aggressive driving behaviors such as pushing a car off the roadway, deliberate obstruction of passing vehicles, pursuing a vehicle, excessive high speed, and tailgating are considered at the top of the list according to the study findings. Most drivers admit that driving $20 \mathrm{~km} / \mathrm{hr}$ above speed limit causes danger to pedestrians but not to other vehicles.

\section{INTRODUCTION AND BACKGROUND}

Despite the efforts made by law enforcement, transportation agencies, and other organizations concerned with roadway safety, traffic accidents and fatalities continue to grow. Roughly 700 people were killed last year on Jordan roadways. This figure is alarming in comparison to the relatively small population of five million and the number of registered vehicles of about half a million. Related research and studies showed that many factors are contributing to traffic accidents and road rage in the Kingdom. These factors include design errors, faulty vehicles, and weather conditions. More importantly, most of the studies identified driving behavior and drivers' attitudes, including excessive speed, to be the major contributing factors to traffic casualties. Aggressive driving has become the norm on our highways. The traveling public frequently sees incidents of road rage on Jordan roadways. 
This study focuses on some of the most important characteristics of Jordanian drivers and attempts to bring attention and to spotlight one of the most dangerous dilemmas threatening the traveling public. This attempt is the first of its kind in the country. Most Jordanians recognize the high risk on their highways. In addition, the majority relates traffic chaos and road rage to aggressive driving. Recent field investigations showed that many traffic incidents could have been avoided with a little patience and a minor yielding to others. The most alarming finding of this study revealed $35 \%$ of respondents reported having been involved in more than one serous traffic accident, with the confession of little or no attempt to change their driving attitude. Running stop signs is considered an offense in Jordan. However, the majority of observed drivers included in the study survey did not stop at a studied stop sign. Some of those drivers were asked at a nearby gas station whether they noticed their offense. Although the sign was very clear, the majority of the questioned drivers admitted that they did not even look for or observe the stop sign. Many of those drivers did not think there was a need for the stop sign at the studied intersection.

\section{Definition of Aggressive Driving}

The following formal definition of aggressive driving is given (Tasca, 2002) at the road user safety branch in the Ontario Ministry of Transportation, Canada:

\section{A driving behavior is aggressive if it is deliberate, likely to increase the risk of collision and is motivated by impatience, annoyance, hostility and/or an attempt to save time.}

This definition is best suited to the Jordanian case where the attempt to buy time is a reality for most Jordanian drivers. Most drivers included in the survey reported that they are often late for work and they are late for appointments most of the time. They gave themselves the unjust priority of being before the others at all times because they thought they were the only ones late and the others all had time at their disposal. Many drivers admitted taking their anger, which is due to road conditions and traffic congestion, out on other drivers. Aggressive driving can refer to any display of aggression by drivers. Moreover, aggressive driving can be defined as the operation of a motor vehicle without regard to others' safety. This aggression can and may lead to extreme acts of physical or mental assault and may cause road rage.

In some cases the drivers are inattentive and would probably be apologetic for their actions. The driver is not considered aggressive in this instance. Aggressive drivers would not feel apologetic because she/he is intentionally ignoring the rights of others on the roadway. That is not saying these actions differ in term of dangerousness. If the victim driver in this case realizes that the act was unintentional, however, she/he would be less likely to retaliate against the inattentive driver. One of the most dangerous consequences of aggressive driving is that it may cause another driver to become angry and retaliate in an extreme manor. This stage of retaliation would be considered road rage.

\section{Definition of Road Rage}

Road rage is considered one of the most extreme detrimental consequences of aggressive driving when a driver becomes angry and retaliates against other aggressive drivers. Road rage can be a result of frustration and anger. The form of road rage may vary from verbal abuse to physical 
violence. Many cases of deaths and serious injuries have been reported in the US due to road rage (Joint, 2003). Jordan is no exception; many traffic accidents involving serious injuries and deaths were a result of road rage. Fist fighting, knives, guns, tools, and other objects were involved in serious disputes that led to casualties on the country's roadways.

\section{STUDY QUESTIONNAIRE}

The study questionnaire included 200 samples. Survey questions ranged from drivers' opinions on whether the listed driving behaviors are aggressive behaviors to a self-opinion on whether the driver is aggressive. Participants were asked to report if they commit such driving acts and to what extent (Table 1). Another group of questions was directed toward a more objective method of identifying aggressive drivers. The willingness of Jordanians to drive $20 \mathrm{~km} / \mathrm{hr}$ over the posted speed was tested using the same sample. Drivers' opinions about some of the consequences of this behavior are reported. The relative scale of $(-3)$ to $(+3)$ was used in the survey, as shown in Table 2. The scale was used to measure the likelihood of the events, where (3 ) was used for less likely, and (+3) used for very likely.

Table 1. Aggressive behavior as judged by Jordanian Drivers

\begin{tabular}{|c|c|c|c|c|c|c|c|c|c|}
\hline \multirow[t]{2}{*}{ Rank } & \multirow[t]{2}{*}{ Aggressive Behavior } & \multicolumn{3}{|c|}{$\%$ of respondents } & \multicolumn{5}{|c|}{ Have you ever conducted this behavior? } \\
\hline & & Yes & NA & No & Never & Seldom & Sometimes & Often & Always \\
\hline 1 & Forcing a car off the roadway & 95 & 5 & & 186 & 10 & 4 & & \\
\hline 2 & $\begin{array}{l}\text { Deliberate obstruction such } \\
\text { as preventing other drivers } \\
\text { from passing }\end{array}$ & 93 & 2 & 5 & 86 & 78 & 36 & & \\
\hline 3 & Forcing a car to pull over & 93 & 3 & 4 & 150 & 46 & 4 & & \\
\hline 4 & Pursuing a vehicle & 92 & 7 & 1 & 100 & 70 & 29 & 1 & \\
\hline 5 & Excessive high speed & 91 & 4 & 6 & 10 & 106 & 50 & 19 & 15 \\
\hline 6 & $\begin{array}{l}\text { Unwillingness to extend } \\
\text { cooperation to others in } \\
\text { severe traffic conditions }\end{array}$ & 90 & 8 & 2 & 170 & 29 & 1 & & \\
\hline 7 & Running red lights & 90 & 6 & 4 & 180 & 18 & 2 & & \\
\hline 8 & Tailgating & 90 & 7 & 3 & 60 & 120 & 16 & 3 & 1 \\
\hline 9 & Yelling and verbal abuse & 88 & 10 & 2 & 10 & 60 & 80 & 35 & 15 \\
\hline 10 & $\begin{array}{l}\text { Improper lane change (e.g., } \\
\text { without signaling) }\end{array}$ & 85 & 10 & 5 & 20 & 75 & 80 & 15 & 10 \\
\hline 11 & Braking suddenly & 84 & 15 & 1 & 30 & 90 & 50 & 21 & 9 \\
\hline 12 & $\begin{array}{l}\text { Collective aggression (e.g., } \\
\text { weddings caravans*) }\end{array}$ & 82 & 7 & 11 & 5 & 105 & 80 & 8 & 2 \\
\hline 13 & $\begin{array}{l}\text { Cutting off or swerving in } \\
\text { front of through traffic from } \\
\text { left-turn lanes }\end{array}$ & 75 & 5 & 20 & 4 & 50 & 70 & 50 & 26 \\
\hline 14 & $\begin{array}{l}\text { Driving slow on the left lane } \\
\text { on multilane roads }\end{array}$ & 74 & 6 & 20 & 21 & 91 & 59 & 25 & 4 \\
\hline 15 & Weaving in and out of traffic & 73 & 20 & 7 & 10 & 59 & 91 & 35 & 5 \\
\hline 16 & Excessive low speed & 69 & 21 & 10 & 33 & 141 & 11 & 9 & 6 \\
\hline 17 & $\begin{array}{l}\text { Failure to yield the right of } \\
\text { way to others }\end{array}$ & 67 & 30 & 3 & 29 & 150 & 21 & & \\
\hline 18 & Glaring & 61 & 27 & 12 & 7 & 116 & 54 & 18 & 5 \\
\hline 19 & Running stop signs & 55 & 40 & 5 & 3 & 24 & 56 & 90 & 27 \\
\hline 20 & Parking on traffic lanes & 54 & 38 & 8 & 25 & 95 & 80 & & \\
\hline
\end{tabular}

$*$ Not significant at $95 \%$ confidence level $\left(\mathrm{t}_{0.025,98}= \pm 1.984\right)$ 
Table 2. Behavior beliefs on speed as seen by Jordanian Drivers

\begin{tabular}{|c|c|c|c|c|c|c|c|c|c|c|}
\hline \multirow[b]{2}{*}{$\begin{array}{l}\text { If I drive } 20 \mathrm{~km} / \mathrm{hr} \text { above the posted } \\
\text { speed of } 70 \mathrm{~km} / \mathrm{hr} \text { on an urban } \\
\text { arterial, then I expect to: }\end{array}$} & \multicolumn{7}{|c|}{$\begin{array}{l}\text { Very } \\
\text { likely } \longleftarrow \text { Likelihood } \longrightarrow \text { likely }\end{array}$} & \multicolumn{3}{|c|}{ Statistic } \\
\hline & +3 & +2 & +1 & $\mathbf{0}$ & -1 & -2 & -3 & $\sum_{\Sigma}^{\bar{E}}$ & 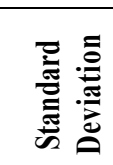 & \begin{tabular}{l}
$\stackrel{0}{ٍ}$ \\
\multirow{2}{\pi}{} \\
1 \\
\end{tabular} \\
\hline $\begin{array}{l}\text { 1. Cause danger to crossing } \\
\text { pedestrians }\end{array}$ & 21 & 17 & 13 & 22 & 18 & 6 & 2 & 0.747 & 1.33 & 5.58 \\
\hline 2. Cause danger to other vehicles & 15 & 9 & 18 & 17 & 23 & 11 & 6 & 0.182 & 1.45 & $1.25^{*}$ \\
\hline $\begin{array}{l}\text { 3. Get caught by police officers for } \\
\text { speeding }\end{array}$ & 2 & 7 & 16 & 20 & 25 & 22 & 7 & -0.545 & 1.05 & -5.16 \\
\hline 4. Cause road rage & 5 & 8 & 28 & 25 & 21 & 8 & 4 & 0.101 & 0.97 & $1.03^{*}$ \\
\hline 5. Reach final destination earlier & 21 & 16 & 25 & 15 & 8 & 10 & 4 & 0.808 & 1.42 & 5.68 \\
\hline 6. Keep up with traffic flow & 15 & 17 & 28 & 26 & 4 & 6 & 3 & 0.828 & 1.10 & 7.51 \\
\hline $\begin{array}{l}\text { 7. Drive safe and comfortable at } 90 \\
\mathrm{~km} / \mathrm{hr} \text { on this road }\end{array}$ & 13 & 20 & 20 & 15 & 18 & 8 & 5 & 0.505 & 1.38 & 3.65 \\
\hline
\end{tabular}

\section{DISCUSSION AND ANALYSIS OF RESULTS}

The analysis focuses on investigating the potential of aggressive driving and road rage among Jordanians. In addition, an attempt is made to relate driver's behavior to traffic conditions on the Kingdom's roadways. Jordanians are assertive in nature. This self assertion is more pronounced on roadways. Any competition from other drivers is considered an intrusion of space.

The prevailing roadway conditions and traffic delay in urban Jordan encourage aggressive drivers and are used by offenders to justify their habits. Some driving behaviors, considered serious traffic offenses in other countries, are believed to be minor in Jordan. Running a stop sign, for example, is a behavior practiced by the majority of Jordanian drivers. Locations of these signs are arbitrary in some cases. Some of these signs are not positioned within drivers' sight and where she or he can stop and clearly see the opposing traffic. Some are covered by trees, posters, and other objects. The survey showed that more than $50 \%$ of drivers in Jordan justify passing on the roadway shoulders. Many of the roadway shoulders are not marked and not well defined.

\section{Aggressive Driving from the Jordanian Perspective}

Table 1 contains common driving behaviors that are considered aggressive by many Jordanian motorists. Although most of these behaviors are common elsewhere in the world, the degree of aggressiveness differs from a Jordanian point of view. Tailgating is considered at the top of the aggressive driving list in Europe (Joint, 2003) and America (Felix, 2002). In Jordan, however, the same item ranks eighth on the list. Tailgating on Jordanian roadways is a common fact even at high speeds. Some items listed in Table 1 draw the attention to a very serious controversial attitude in behavioral theory. Surveyed drivers agreed some driving behaviors are aggressive. 
More than $50 \%$ of these drivers admitted practicing the same aggressive behaviors. This leads to the conclusion that those drivers are aggressive drivers.

Jordanians' views on speeding within the context of aggressive driving differ greatly from views in Europe and America. The item of speeding ranks sixth on the list (Table 1). Many surveyed drivers admitted to regularly driving over the speed limit. Eighty percent of surveyed drivers reported to love driving at high speed. This is particularly true in the Jordanian case where most of the population is young.

Aggressive behaviors described by questions nine, ten, thirteen, and fifteen are related to changing lanes, weaving, and verbal abuse (Table 1). These behaviors are of particular importance in the study where more than $50 \%$ of the respondents admitted their regular involvement in such aggressive behaviors. Question thirteen in particular scored the highest, where 146 out of the 200 respondents confessed to regular cutting off through traffic from leftturn lanes. This particular aggressive behavior is often encouraged by deficient geometric design procedures where through traffic lanes suddenly turn into left-turn lanes in many cases. Other behaviors are rated highly as forms of aggressive driving, but most respondent reported that they are less likely to carry out such acts (Questions 1, 3, 5, and 7 in Table 1). Running stop signs is considered an aggressive driving behavior by only $55 \%$ of the interviewed drivers. Beeping the horn and flashing headlights are not considered aggressive driving behaviors by most respondents.

Table 2 shows interesting information on Jordanians' perspective on driving over the posted speed. Questions one through seven regard driving $20 \mathrm{~km} / \mathrm{hr}$ above the speed limit; five (Questions 1, 3, 5, 6, 7) are considered significant by t-test with confidence level of 95\%. Four of the five questions $(1,5,6$, and 7$)$ have a positive likelihood, while question three showed less likelihood. This suggests drivers are very optimistic when it comes to being caught by law enforcement officers. Jordanians are aware of causing danger to pedestrians while driving 20 $\mathrm{km} / \mathrm{hr}$ above the posted speed. On the other hand, they do not acknowledge the danger to other vehicles at $20 \mathrm{~km} / \mathrm{hr}$ above the speed limit. This implies that they feel overly secure and protected in their own vehicles. Question six, related to keeping up with traffic flow, has the highest positive significance among all other questions. This insinuates that it is acceptable to drive $20 \mathrm{~km} / \mathrm{hr}$ to keep up with other vehicles. Many of the respondents suggest that $20 \mathrm{~km} / \mathrm{hr}$ above the posted speed is safe and comfortable (Question 7). This is further emphasized in question four where most of the respondents believe that $20 \mathrm{~km} / \mathrm{hr}$ above will not cause road rage.

\section{CONCLUSIONS AND RECOMMENDATIONS}

The attempt to evaluate and assess driving aggression and road rage in Jordan should include drivers' attitudes, roadway conditions, traffic conditions and personal circumstances. This task is very difficult when trying to use quantitative measures in the process. The amount of research conducted in this field worldwide and particularly in Jordan is limited to field surveys using small portions of the population. This study is the first of its kind to address aggressive driving issues in Jordan. Saving time, territorial behavior, and traffic congestion are some of the main factors contributing to aggressive driving in Jordan. 
The findings of this study can be summarized as follows:

1. Aggressive driving is believed to contribute to the high accident rate and traffic casualties in Jordan.

2. Aggressive driving leads to retaliatory actions, and therefore, causes road rage.

3. Most respondents admitted that their aggressiveness was a temporary measure used to retaliate against other drivers' aggression.

4. Self-assertion and territorial attitude among Jordanians leads to aggressive driving on the Kingdom's roadways.

5. The rate of aggressive driving is much higher than in western countries.

6. Road conditions and traffic factors contribute to aggressive driving in Jordan.

7. Forcing a car off the roadway, deliberate obstruction of passing vehicles, excessive speed, running red lights, and tailgating are ranked highest as aggressive driving behaviors by Jordanians.

8. Beeping the horn and flashing headlights are not considered by Jordanians to be aggressive driving behaviors.

Further research is recommended in the area of aggressive driving on Jordanian roadways.

Quantitative measures should be used to relate the attitude of common drivers to road aggression and road rage. Behavioral theory can be used to assist researchers in this field. Research in this area can be made more effective through the use of multi-disciplinary approaches.

\section{REFERENCES}

Felix, Benedicate et al. (2002). An Educational Programme for Aggressive Drivers, Brussels, Belgium.

Joint, Matthew. (1997). Aggressive Driving: Three Studies, Road rage. Washington, D.C.: AAA Foundation for Traffic Safety.

Jordan Traffic Institute. (2002). Traffic Accidents in Jordan 2002. Ministry of Interior, Public Security Directorate, Amman, Jordan.

Tasca, Leo. (2002). A review of the Literature on Aggressive Driving Research. Ontario, Canada: Ontario Advisory Group on Safe Driving Secretariat. 